\title{
Recent climate change in Japan - spatial and temporal characteristics of trends of temperature
}

\author{
D. Schaefer and M. Domroes \\ Department of Geography, Mainz University, 55099 Mainz, Germany \\ Received: 7 February 2008 - Published in Clim. Past Discuss.: 21 April 2008 \\ Revised: 12 December 2008 - Accepted: 12 December 2008 - Published: 9 February 2009
}

\begin{abstract}
In this paper temperature series of Japan were statistically analysed in order to answer the question whether recent climate change can be proved for Japan; the results were compared and discussed with the global trends. The observations in Japan started for some stations in the 1870s, 59 stations are available since 1901, 136 stations since 1959. Modern statistical methods were applied, such as: Gaussian binominal low-pass filter (30 yr), trend analysis (linear regression model) including the trend-to-noise-ratio as measure of significance and the non-parametric, non-linear trend test according to MANN (MANN's Q).

According to the results of the analyses, climate change in Japan is clearly shown for temperature over the $100 \mathrm{yr}$ (1901-2000): Annual mean temperatures increased at all stations from 0.35 (Hakodate) to $2.95^{\circ} \mathrm{C}$ (Tokyo). The magnitude of climate change is illustrated to increase over the recent period 1976-2000. Seasonally, the strongest warming trends were observed for winter temperatures and also increasing temperature trends prevailed in summer, with the exception of slightly decreasing trends at only four stations.
\end{abstract}

\section{Introduction}

"Global warming" and "climate change" are major keywords in the present-day global change discussion. Emissions of greenhouse gases and aerosols due to human activities continue to alter the atmosphere commonly recognized to affect the climate. The concentration of carbon dioxide in the atmosphere has increased by more than 30 percent since 1750 . These developments have the potential of raising global surface temperatures and, in consequence, they impact other parts of the climate system. It is commonly accepted that

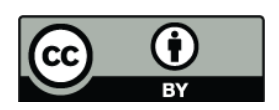

Correspondence to: D. Schaefer (Dirk.Schaefer@Uni-Mainz.de) the global average surface air temperatures have risen by $0.74^{\circ} \mathrm{C}\left[0.56^{\circ} \mathrm{C}\right.$ to $\left.0.92^{\circ} \mathrm{C}\right]$ over the last $100 \mathrm{yr}$ from $1906-$ 2005 (IPCC, 2007). The corresponding trend for the observation period $1901-2000$ is $0.6^{\circ} \mathrm{C}\left[0.4^{\circ} \mathrm{C}\right.$ to $\left.0.8^{\circ} \mathrm{C}\right]$ underling the general strengthening of the warming trend during the last decades: Eleven of the last twelve years (19952006) rank among the 12 warmest years in the instrumental record of global surface temperature (since 1850) (IPCC, 2007). Although the temperature increase is widespread over the globe, spatial and temporal characteristics of temperature trends can be found with highest values in northern latitudes; additionally, land regions have warmed faster than the oceans (IPCC, 2007). Therefore, climate change and its impacts are an issue of a great and rapidly accelerating concern since the 1990s. Because of the spatial and temporal distinctions of temperature trends, it is very important to analyse station data for a better understanding of trend behaviours on regional and local scales.

So far, some studies have analysed temperature records in Japan in recent years: A general warming was found, for example by Yue and Hashino (2003) who showed increasing trends of monthly temperature in Japan for 46 stations from 1900-1996. Fujibe (1995) reported about rising temperature trends at 60 Japanese cities (1891-1992) and their relationship with urbanisation: Medium sized cities showed increasing minimum temperatures at a rate of about $1^{\circ} \mathrm{C} / 100$ years whereas large cities experienced a much stronger warming of $2-5^{\circ} \mathrm{C} / 100$ years. Maximum temperatures also increased but with a smaller magnitude. Kato (1996) applied principal component analysis to separate the impacts of urbanization from station data. According the analysis of the data of 51 stations (1920-1992) the urban increase counts 1.0$2.5^{\circ} \mathrm{C} / 100$ years.

In a recent paper Fujibe et al. (2007) reported about longterm changes of temperature extremes and the day-to-day variability in Japan by analysing the records of 17 climate stations (1931-2005). According to their study, minimum

Published by Copernicus Publications on behalf of the European Geosciences Union. 


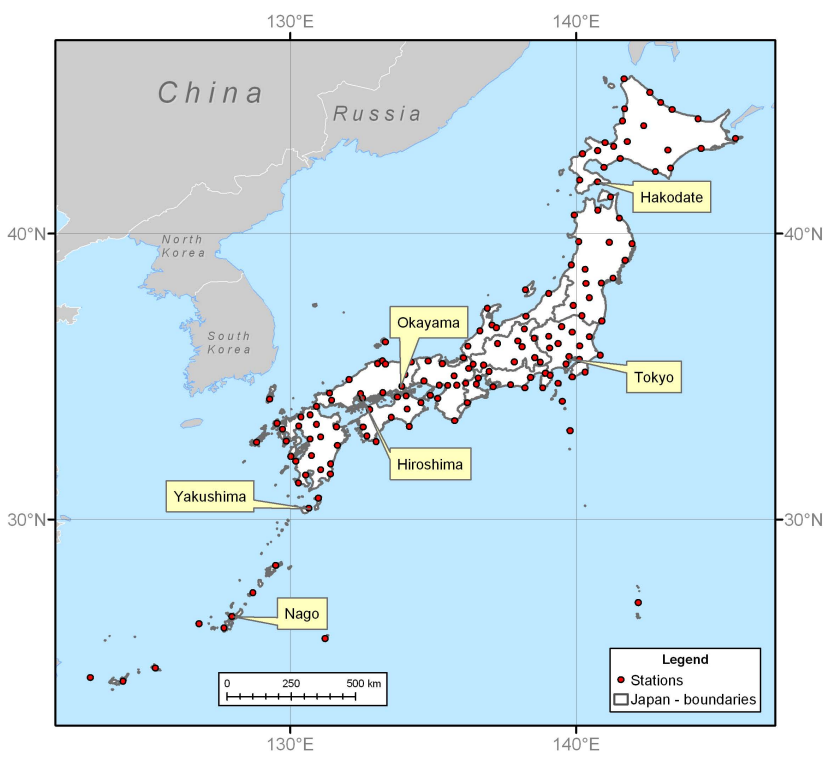

Fig. 1. Location of stations under study.

temperature shows a strong increase of temperature, especially for the monthly lowest value $\left(0.27^{\circ} \mathrm{C} /\right.$ decade for $1931-$ 2005 and $0.51^{\circ} \mathrm{C} / \mathrm{decade}$ for $\left.1981-2005\right)$. The day-to-day variability of minimum temperatures is decreasing. Maximum temperature shows increasing trends at a lower rate $\left(0.08^{\circ} \mathrm{C} /\right.$ decade for $1931-2005$ and $0.4-0.5^{\circ} \mathrm{C} /$ decade for 1981-2005); besides, there is no trend in the day-to-day variability (Fujibe et al., 2007).

In addition to the general warming in Japan articles about the role of external forcings can be found. The temperature after a great volcanic eruption (dust veil index $>200$ ) averages in summer $1.3 \pm 0.5^{\circ} \mathrm{C}$ lower than in normal years, while in northern mid-latitudinal mean surface air temperature decrease about $0.2^{\circ} \mathrm{C}$ (Kondo, 1988). Kurihara (2000) reported of a quasi-six-year fluctuation of high summer temperatures in Japan which are related to the fluctuations of sea surface temperature in the North Pacific Ocean.

The aim of this paper is (1) to analyse mean temperature series of a dense network of stations in Japan in a detailed way in order to investigate the spatial and temporal characteristics of temperature change in Japan and (2) to compare and discuss the results with global trends.

\section{Data and methods}

Daily mean temperature series for 155 stations were provided by the National Climatic Data Center, USA (2006). The data have been quality checked by the National Climatic Data Center. According to Yue and Hashino (2003) no significant changes in the instrumentation of the stations or the observation practice have been observed. Instrumental observations started for some stations in the 1870s, 59 stations are available since 1901 and 136 stations from 1959 onwards. Japan can be considered as ideal for climate change studies as sufficient and detailed (daily) temperature series are kept at diverse locations scattered across the islands (Fig. 1). The global temperature anomalies were taken for a comparison of the results with global temperature trends (Brohan et al., 2006). Three observation periods were investigated: 19012000 (100 yr), 1951-2000 (50 yr) and 1976-2000 (25 yr) in order to find out if the global observations of strengthened warming trends during the last decades can be confirmed for Japan. The periods were individually studied and compared with each other, applying the common international practice of climate change studies. Computations were carried out for annual, winter and summer data, referring to the following seasons:

- winter, December-February;

- spring, March-May;

- summer, June-August;

- autumn, September-November.

The following statistical methods of time series analysis were applied, which are commonly used for global climate change research in order to analyse the trends of spatial and temporal variabilities of temperature over Japan: As emphasised by the World Meteorological Organisation (Mitchell et al., 1966) the Gaussian binominal low-pass filter that suppresses high-frequency oscillations (30 yr) was applied to smooth the data. The linear trend analysis (the least square method) was computed to measure the magnitude of longterm linear trends. In this study, the linear regression model was applied for annual and seasonal data (for all three time periods under study: 1901-2000, 1951-2000, and 19762000); the regression coefficients are given in ${ }^{\circ} \mathrm{C}$. As a measure of significance the trend-to-noise-ratio $(T / N)$ was calculated: The trend value is divided by the noise, where the noise is represented by the standard deviation of the data. $T / N$ values $>1.96$ can be regarded as statistically significant (95\%) (Sneyers, 1990). Additionally, the non-parametric, nonlinear trend test according to MANN (MANN's $Q$ ) was computed to detect all trends, no matter what form they have (Mann, 1945). This trend test was modified by Kendall (Kendall, 1970) and makes no assumption of a statistical distribution of the analysed data (Sneyers, 1990). MANN's $Q$ values $>1.96$ can be regarded as significant $(95 \%)$.

\section{Results}

\subsection{The case study Tokyo}

The official meteorological station Tokyo was taken for a case study because of its long observation period covering $125 \mathrm{yr}$ from 1876-2000. Annual mean temperature shows 


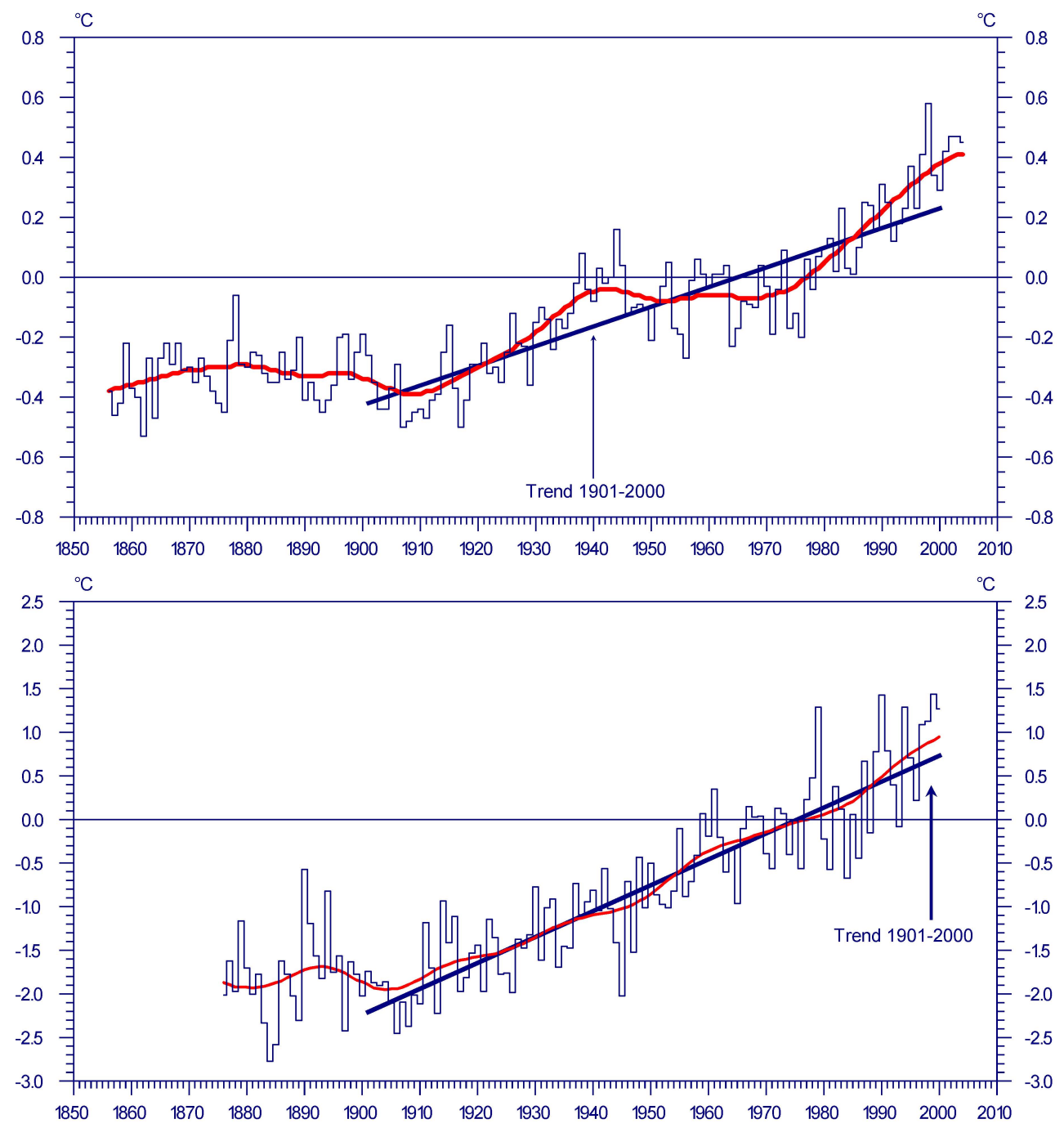

Fig. 2. Mean global temperature anomalies (top) and mean annual temperature anomalies at Tokyo (bottom) along with low-pass filtered values/30 yr (red curve) and trend lines, 1901-2000; notice different scales of the y-axis.

a strongly increasing trend during the last century with the 1990s as the warmest decade in the series (Fig. 2). The warmest year on record was 1999, with a temperature of $1.44^{\circ} \mathrm{C}$ over the long-term 1961-1990 mean. Most of the warmest years of the period under study (1876-2000) were experienced during the 1990s (Fig. 2). The trend line indicates an almost linear trend of the mean annual temperature over the $100 \mathrm{yr}$ observation period 1901-2000 (Fig. 2). A general increase of the temperatures can be clearly manifested from about 1905 onwards; the slightly decreasing global temperatures from 1946-1975 can not be determined for Tokyo temperatures (Fig. 2). For the $125 \mathrm{yr}$ (1876-2000), the warming trend in Tokyo is confirmed by the results of trend computation and can be quantified by an increasing trend at a rate of $2.93^{\circ} \mathrm{C}$ (or $0.24^{\circ} \mathrm{C}$ per decade), which is almost five time higher than the global trend $\left(0.05^{\circ} \mathrm{C}\right.$ per decade, see Table 1 and Fig. 2). According to the $T / N$-value of 2.96 the linear trend can be taken as highly significant trend (>99\%). The warming trend of mean annual temperature continued and even strengthened in the last decades, which can be clearly shown by the computed trend values per decade increasing from $0.34^{\circ} \mathrm{C}$ to $0.52^{\circ} \mathrm{C}$ for the periods 1951-2000 and 1976-2000, respectively (Table 1). Strongly increasing trends of temperature can be manifested in seasonal respects with highest values for winter and autumn (Table 1). All computed seasonal temperature trends over the $125 \mathrm{yr}$ study period $(1876-2000)$ are linear $(T / N>1.96)$ and significant ( $T / N>1.96$; MANNs $Q>1.96)$. Warming of seasonal temperatures is also strengthened during the more recent times: The rate of warming of winter temperatures over the last $25 \mathrm{yr}(1976-2000)$ is much higher than over the last $50 \mathrm{yr}(1951-2000)$, namely $0.73^{\circ} \mathrm{C}$ vs. $0.52^{\circ} \mathrm{C}$ per decade (Table 1). At the same time, the $T / N$-values are slightly decreasing (Table 1). This means that the trends 
Table 1. Annual and seasonal temperature trends per decade, the trend-to-noise-ratios (T/N) and MANNs Q (Q) in Tokyo (top) and for the global temperature anomalies (bottom); trends over the whole observation period are given in brackets.

\begin{tabular}{lccccccccc}
\hline & \multicolumn{3}{c}{$1901-2000$} & \multicolumn{3}{c}{$1951-2000$} & \multicolumn{3}{r}{$1976-2000$} \\
\hline Tokyo & Trend & $\mathrm{T} / \mathrm{N}$ & $\mathrm{Q}$ & Trend & $\mathrm{T} / \mathrm{N}$ & $\mathrm{Q}$ & Trend & $\mathrm{T} / \mathrm{N}$ & $\mathrm{Q}$ \\
Annual & $0.30(2.95)$ & 3.06 & 10.70 & $0.34(1.67)$ & 2.45 & 5.38 & $0.52(1.24)$ & 1.85 & 2.83 \\
Winter & $0.40(3.96)$ & 2.78 & 9.01 & $0.52(2.59)$ & 2.47 & 5.42 & $0.73(1.82)$ & 1.90 & 2.80 \\
Spring & $0.29(2.86)$ & 2.72 & 8.76 & $0.25(1.24)$ & 1.60 & 3.76 & $0.45(1.07)$ & 1.30 & 1.96 \\
Summer & $0.21(2.13)$ & 2.09 & 6.24 & $0.21(1.05)$ & 1.18 & 2.31 & $0.44(1.07)$ & 1.04 & 1.96 \\
Autumn & $0.30(2.95)$ & 2.66 & 8.71 & $0.42(2.04)$ & 2.20 & 4.98 & $0.60(1.43)$ & 1.61 & 2.64 \\
Global & Trend & $\mathrm{T} / \mathrm{N}$ & $\mathrm{Q}$ & Trend & $\mathrm{T} / \mathrm{N}$ & $\mathrm{Q}$ & Trend & $\mathrm{T} / \mathrm{N}$ & $\mathrm{Q}$ \\
Annual & $0.07(0.66)$ & 2.91 & 9.92 & $0.10(0.47)$ & 2.57 & 5.78 & $0.18(0.43)$ & 2.65 & 4.46 \\
Winter & $0.07(0.69)$ & 2.64 & 8.46 & $0.11(0.52)$ & 2.28 & 5.01 & $0.20(0.48)$ & 2.51 & 4.16 \\
Spring & $0.07(0.73)$ & 2.88 & 9.84 & $0.11(0.53)$ & 2.58 & 6.01 & $0.19(0.46)$ & 2.60 & 4.61 \\
Summer & $0.06(0.61)$ & 2.81 & 9.46 & $0.09(0.45)$ & 2.50 & 5.74 & $0.19(0.46)$ & 2.57 & 4.31 \\
Autumn & $0.06(0.59)$ & 2.77 & 9.25 & $0.08(0.40)$ & 2.31 & 4.99 & $0.15(0.36)$ & 2.25 & 3.30 \\
\hline
\end{tabular}

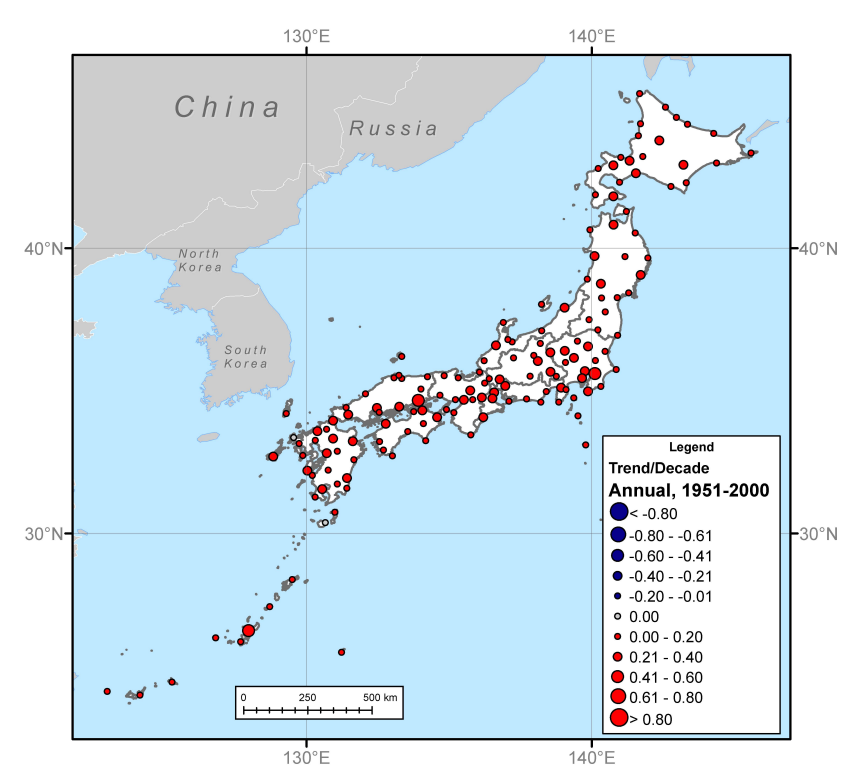

Fig. 3. Trends/decade of mean annual temperature $\left[{ }^{\circ} \mathrm{C}\right], 1951-$ 2000 .

are not strictly linear because of their high interannual variability. In any case, the trends are positive and significant (MANNs $Q>1.96$ ). The computed seasonal temperature trends in Tokyo (1976-2000) are higher than the corresponding values of the global temperature anomalies, in case of winter and autumn even three times higher (Table 1). However, the computed trends for the more recent period (19762000) are not linear but significantly positive (Table 1). In summary, annual and seasonal temperatures in Tokyo have risen over the $125 \mathrm{yr}$ study period (1876-2000) and also over the more recent periods (1951-2000 and 1976-2000, respectively). The warming trends in Tokyo are intensified in the last decades. Compared with global trends, general similari-

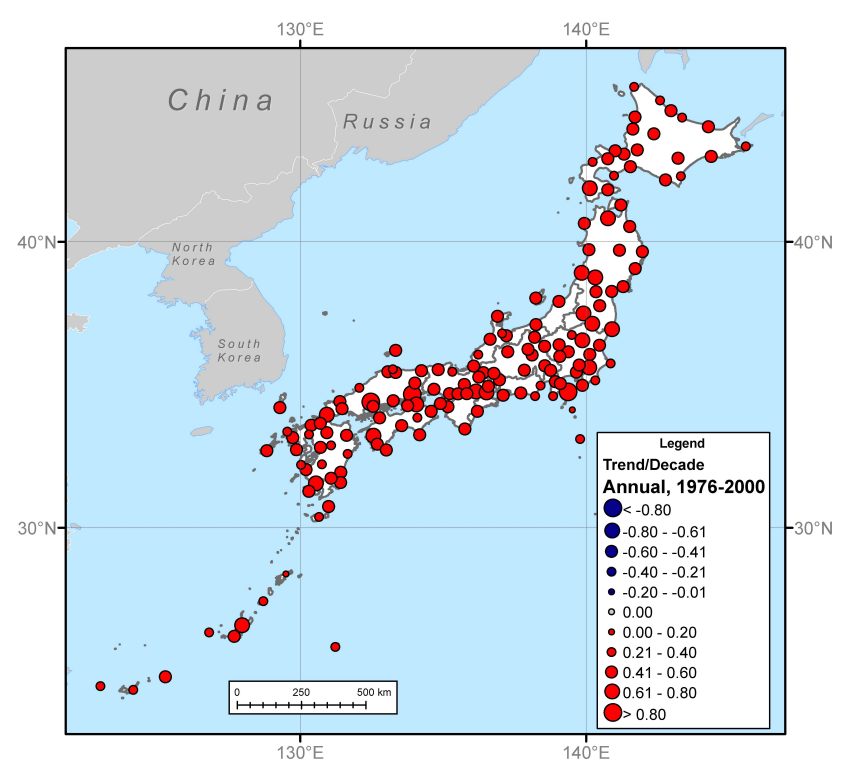

Fig. 4. Trends/decade of (mean) annual temperature $\left[{ }^{\circ} \mathrm{C}\right], 1976-$ 2000 .

ties can be found: It can be observed that the highest positive temperature trends are experienced in winter, whereas the trends in summer are also positive but with a smaller magnitude. It is noticeable to mention that the magnitude of all temperature trends in Tokyo is much higher compared with the global temperature anomalies and the computed trends are significant linear over the total observation period (18762000). 


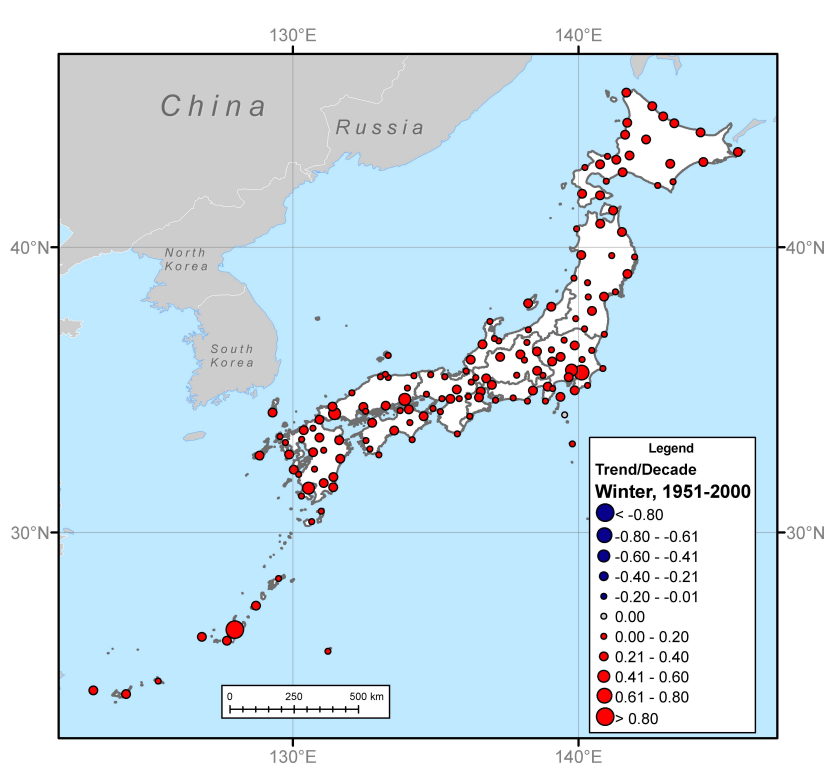

Fig. 5. Trends/decade of mean winter temperature $\left[{ }^{\circ} \mathrm{C}\right], 1951-$ 2000 .

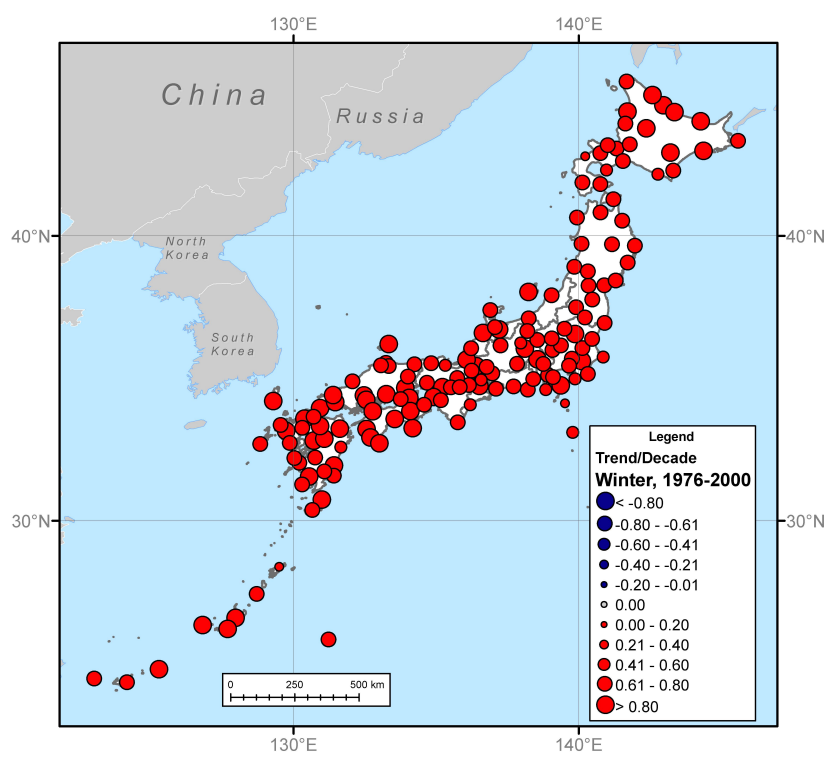

Fig. 6. Trends/decade of mean winter temperature $\left[{ }^{\circ} \mathrm{C}\right], 1976-$ 2000.

3.2 Spatial and temporal characteristics of temperature trends in Japan

\subsubsection{Mean annual temperature trends in Japan}

According to the results of the trend computations for all stations under study, climate change in Japan is clearly shown for temperature over the past $100 \mathrm{yr}$ (1901-2000): Annual mean temperatures increased at all (59) stations from 0.35 (Hakodate) to $2.95^{\circ} \mathrm{C}$ (Tokyo), or $0.04^{\circ} \mathrm{C}$ and $0.30^{\circ} \mathrm{C} /$ decade,

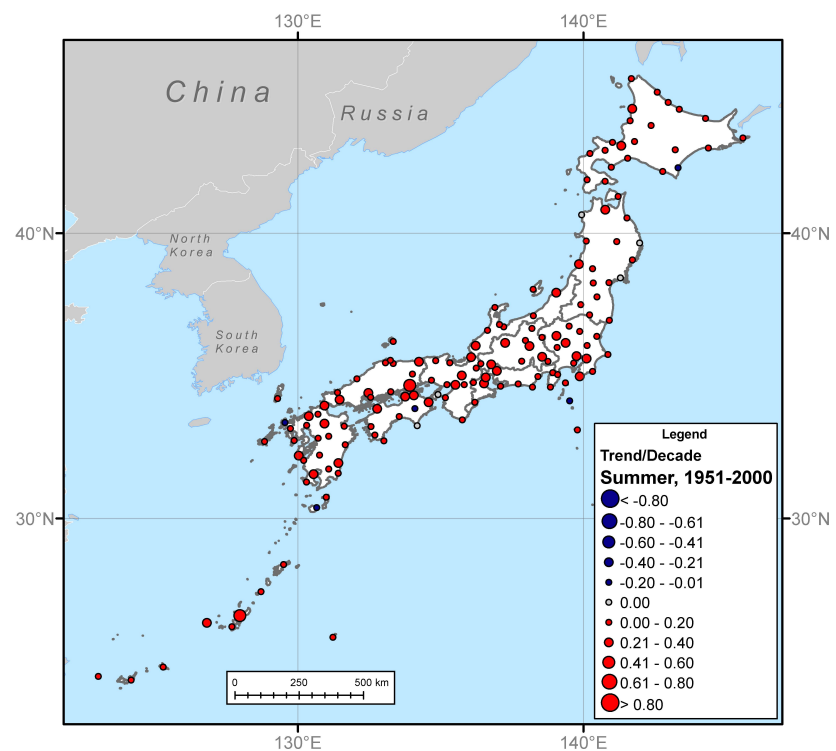

Fig. 7. Trends/decade of mean summer temperature $\left[{ }^{\circ} \mathrm{C}\right], 1951-$ 2000.

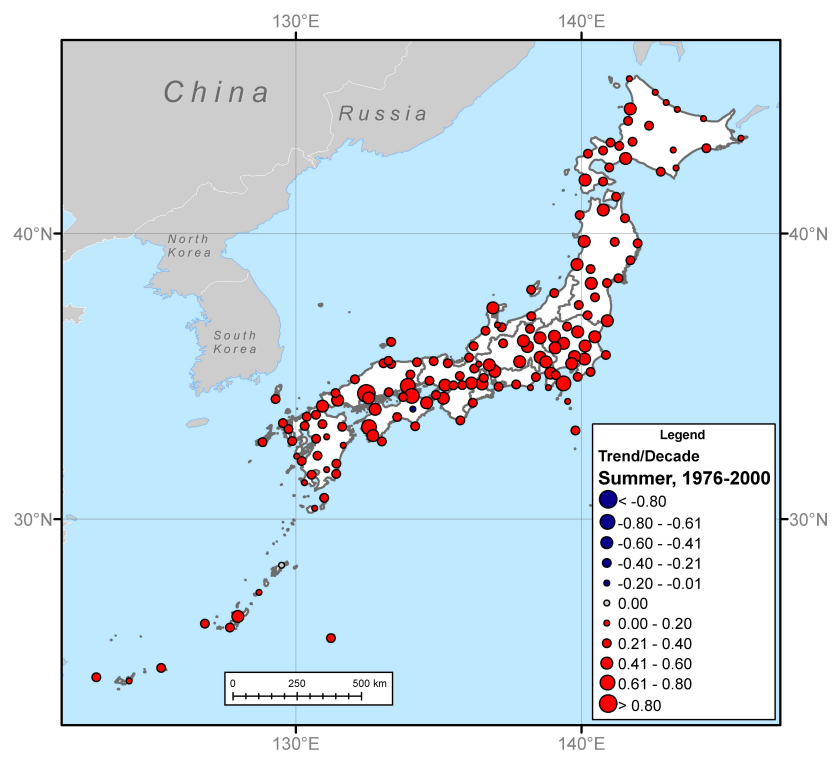

Fig. 8. Trends/decade of mean summer temperature $\left[{ }^{\circ} \mathrm{C}\right], 1976-$ 2000.

respectively. The trends are at 42 stations (or 70\%) significantly linear $(T / N$-values $>1.96)$. However, the temperature rise is pronounced: $98 \%$ of the trends are significant positive (according to MANNs $Q>1.96$ ). Positive trends of temperature prevail in Japan also for the $50 \mathrm{yr}$ period (1951-2000; see Fig. 3): The highest temperature rise was observed in Okayama with $2.14^{\circ} \mathrm{C}$ (resp. $0.44^{\circ} \mathrm{C} /$ decade). $84 \%$ (or 114 out of 136 stations) of the trends are not strictly linear but $69 \%$ (or 94 stations) are significantly positive (according to the MANNs $Q$ values $>1.96$ ). For the 
study period 1976-2000, positive temperature trends were observed at all stations under study and the magnitude of climate change is seen to increase (Fig. 4). The highest temperature warming was observed in Hiroshima with $2.35^{\circ} \mathrm{C}$ (resp. $0.98^{\circ} \mathrm{C} / \mathrm{decade}$ ), a value which is almost five times higher than the global trend. In any case, $34 \%$ of the computed trends are linear and $87 \%$ significantly positive. As far as annual temperatures are concerned, a distinct increase could be shown over the secular period (1901-2000) with a strong trend of warming over the recent period (1976-2000).

\subsubsection{Mean winter temperature trends in Japan}

Analysing seasonal trends (of mean temperatures) the strongest warming trends were observed in winter season corresponding with the global trends (Fig. 5). All computed trends were positive during the $50 \mathrm{yr}$ period (1951-2000) showing even higher values than the trends of the annual temperature. Again, Tokyo shows the highest increasing trend with $2.46^{\circ} \mathrm{C}$ (resp. $0.50^{\circ} \mathrm{C} /$ decade). Although all computed trends are positive, only the computed trend at Tokyo is linear indicating however a high interannual variability. $46 \%$ of the trends are significant (according MANNs $Q$ ). The warming trend in winter is strengthened during the last decades (19762000) resulting in the highest computed temperature trends in this analysis (Fig. 6): Temperatures in Nago increased linear at a rate of $2.81^{\circ} \mathrm{C}$ (resp. $1.12^{\circ} \mathrm{C} /$ decade). Because of the high interannual variability only $6 \%$ of the computed trends are linear but $80 \%$ are significant (according to MANNs $Q$ ).

\subsubsection{Mean summer temperature trends in Japan}

In summer, increasing trends of temperature prevail at all stations, but also slightly decreasing trends were observed at five stations (1951-2000): Its magnitude varies between a decrease of $-0.52^{\circ} \mathrm{C}$ (resp. $-0.11^{\circ} \mathrm{C} /$ decade) at Yakushima and $2.01^{\circ} \mathrm{C}$ (resp. $0.41^{\circ} \mathrm{C} /$ decade) at Okayama (Fig. 7). Due to the high interannual variability not all trends are significantly linear. The increasing trends of summer temperatures as already shown for the study period 1951-2000 are intensified during the period 1976-2000 (Fig. 8). Hiroshima experienced the highest positive trend at a rate of $2.36^{\circ} \mathrm{C}$ (resp. $0.98^{\circ} \mathrm{C} /$ decade). Only at four stations the computed trends were significantly linear and at most stations not significant (according to MANNs $Q$ ).

\section{Discussion}

The case study of Tokyo shows increasing trends of temperature over all periods of observation (1876-2000, 1901-2000, 1951-2000, 1976-2000). The mean annual temperature shows an increasing trend of $2.93^{\circ} \mathrm{C}$ (resp. $0.24^{\circ} \mathrm{C} /$ decade) during the period 1876-2000 whereas the trend for the global mean temperatures is $0.59^{\circ} \mathrm{C}$ (resp. $0.05^{\circ} \mathrm{C} /$ decade)
Strongly increasing trends can be observed during all seasons, with highest trends in winter (corresponding with global trends). The warming trends in Tokyo were intensified in the last decades. The trend for the annual temperature (1976-2000) in Tokyo $\left(0.52^{\circ} \mathrm{C} / \mathrm{decade}\right)$ is almost three times higher than for the global temperature anomalies $\left(0.18^{\circ} \mathrm{C} /\right.$ decade $)$. The magnitude of all temperature trends in Tokyo is much higher compared with the global temperature anomalies.

For Japan as a whole, climate warming is clearly shown over all periods of observation (1901-2000, 1951-2000, 1976-2000). During the $100 \mathrm{yr}$ (1901-2000) mean annual temperatures increased at all stations from 0.35 (Hakodate) to $2.95^{\circ} \mathrm{C}$ (Tokyo). Strongly increasing trends can be found in all seasons, with highest increasing trends in winter. The magnitude of climate change is illustrated to increase over the recent period 1976-2000, which can be clearly identified by the case of Tokyo and also for the other stations under study. The temperature series in Japan show remarkable correlations with the global temperature anomalies, explaining a great correspondence between the recent trends of warming in Japan with global warming underlining the highest values in winter. However, the magnitude of the computed trends in Japan is much higher than the global temperature anomalies. Increasing temperature trends can be observed in large parts of East Asia as shown in a detailed investigation for China for the observation period 1951-2000 (Schaefer, 2001; Domroes and Schaefer, 2003): Annual temperature trends increase mostly between $0.5-1.0^{\circ} \mathrm{C}(1951-2000)$ with the highest magnitudes over the northeastern and northwestern parts of China. Annual temperature increase results mainly from the marked increase in winter temperatures and the positive temperature trends in spring and summer, while slight decreases are experienced in summer. Thus the observations for China correspond with global trends, too. The fact that the temperature increase in China appears to be growing faster than the global temperatures corresponds with the marked warming in Japan.

The observations on recent climate change in Japan must be regarded with great concern on the human and natural environment. However, the observed warming in Japan might be superposed by other forcings like the urban heat island (Fujibe, 1995; Kato, 1996). It is from the statistical point of view difficult to filter out and quantify the urban heating effects out of the station data. Therefore, the separation of urban and global temperature signals remains as a subject of future studies (Fujibe et al., 2007). Even though the data have been quality checked by the National Climatic Data Center, possible inhomogeneities caused by station moves may influence trend (Mitchell et al., 1966; Fujibe, 1995; Pielke et al., 2007). Accordingly further investigations have to be carried out to deepen the observations and also to analyse the forcings of the observed increasing temperature trends in Japan. 
Acknowledgements. Parts of the results of this paper were achieved during a research visit of D. Schaefer at the Tokyo Metropolitan University. The authors want to express their sincerest thanks to the Japan Society for the Promotion of Science (JSPS) for supporting the Joint Research Project about "Recent Climate Change and Extreme Weather Events in East Asia" with T. Mikami (Tokyo Metropolitan University) and his research group on climatology.

Edited by: D.-D. Rousseau

\section{References}

Brohan, P., Kennedy, J. J., Harris, I., Tett, S. F. B., and Jones, P. D.: Uncertainty estimates in regional and global observed temperature changes: a new dataset from 1850, J. Geophys. Res., 111, D12106, doi:10.1029/2005JD006548, 2006.

Domroes, M. and Schaefer, D.: Variability of climatic change over time and space in China, in: Climates in Transition, edited by: Nkemdirim, L., Commission on Climatology, International Geographical Union, 55-66, 2003.

Fujibe, F.: Temperature rising trends at Japanese cities during the last hundred years and their relationship with population, population increasing rates and daily temperature ranges, Pap. Meteorol. Geophys., 46, 35-55, 1995.

Fujibe, F., Yamazaki, N., Kobayashi, K., and Nakamigawa, H.: Longterm changes pf temperature extremes and day-to-day variability in Japan, Pap. Meteorol. Geophys., 58, 63-72, 2007.

Griffiths, G. M., Chambers, L. E., Haylock, M. R., Manton, M. J., Nicholls, N., Baek, H.-J., Choi, Y., Della-Marta, P. M., Gosai, A., Iga, N., Lata, R., Laurent, V., Maitrepierre, L., Nakamigawa, H., Ouprasitwong, N., Solofa, D., Tahani, L., Thuy, D. T., Tibig, L., Trewin, B., Vediapan, K., and Zhai, P.: Change in mean temperature as a predictor of extreme temperature change in the AsiaPacific region, Int. J. Climatol., 25, 1301-1330, 2005.

IPCC: Climate Change 2001: Synthesis Report, A Contribution of Working Groups I, II, and III to the Third Assessment Report of the Integovernmental Panel on Climate Change, edited by: Watson, R. T. and the Core Writing Team, Cambridge University Press, Cambridge, UK, and New York, NY, USA, 398 pp., 2001.

IPCC: Climate Change 2007: The Physical Science Basis, Contribution of Working Group I to the Fourth Assessment Report of the Intergovernmental Panel on Climate Change, edited by: Solomon, S., Qin, D., Manning, M., Chen, Z., Marquis, M., Averyt, K. B., Tignor, M., and Miller, H. L., Cambridge University Press, Cambridge, UK and New York, NY, USA, 996 pp., 2007.
Kato, H.: A statistical method for separating urban effect trends from observed temperature data and its application to Japanese temperature records, J. Meteorol. Soc. Jpn., 74, 639-653, 1996.

Kendall, M. G.: Rank Correlation Methods, Griffin, London, 202 pp., 1970.

Kondo, J.: Volcanic Eruptions, Cool Summers, and Famines in the Northeastern Part of Japan, J. Climate, 8, 775-788, doi:10.1175/1520-0442, 1988.

Kurihara, K.: Quasi-six-year Fluctuation in Summer Surface Air Temperatures in Japan, J. Meteor. Soc. Jpn., 81(5), 1289-1297, 2003.

National Climatic Data Center, USA: Global Historical Climatology Network. Daily Version 1.0., online available at: ftp://ftp. ncdc.noaa.gov/pub/data/ghcn/daily/, last access: 14 November 2005.

Mann, H. B.: Nonparametric Tests against Trend, Econometrica, 13, 245-259, 1945.

Mitchell, J. M., Dzerdzeevskii, B., Flohn, H., Hofmeyr, W. L., Lamb, H. H., Rao, K. N., and Wallen, C. C.: Climatic change, Technical Note No. 79, World Meteorological Organization, Geneva, 79 pp., 1966.

Pielke, R. A., Davey, C. A., Niyogi, D., et al.: Unresolved issues with the assessment of multidecadal global land surface temperature trends, J. Geophys. Res., 112, D24S08, doi:10.1029/2006JD008229, 2007.

Schaefer, D.: Climate Change in Sri Lanka? Statistical Anaylses of Long-term Temperature and Rainfall Records, in: Sri Lanka, Past and Present, edited by: Domroes, M. and Roth, H., Archaeology, Geography, Economics, Weikersheim (Margraf), Germany, 103117, 1998.

Schaefer, D.: Rezente Klimaänderungen in China? Ein Vergleich mit globalen Trends, Geographische Rundschau, 10, 42-46, 2001.

Sneyers, R.: On the Statistical Analysis of Series of Observations. Technical Note No. 143, World Meteorological Organization, Geneva, Switzerland, 1990.

Yue, S. and Hashino, M.: Temperature trends in Japan, 1900-1996, Theor. Appl. Climatol., 75, 15-27, 2003. 